\title{
ИЗМЕНЕНИЯ В ПРОЦЕССАХ ИНТЕЛЛЕКТУАЛЬНОЙ И ТРУДОВОЙ ДЕЯТЕЛЬНОСТИ В СОВРЕМЕННОЙ ЭКОНОМИКЕ
}

\author{
(c) 2020 Левченко Лариса Владимировна \\ кандидат экономических наук, доцент \\ Самарский государственный экономический университет, Россия, Самара \\ E-mail: lvls@mail.ru
}

В работе проводится исследование изменений в современных видах интеллектуальной и трудовой деятельности. Рассматриваются их особенности, современные изменения и тенденции дальнейшего развития. Также в работе приводится фактический статистический материал по научной деятельности и затрагивается актуальная в настоящее время проблема самозанятости населения.

Ключевые слова: человеческий капитал, интеллектуальный капитал, интеллектуальная деятельность, инновационная деятельность, самозанятость, формализованное знание, гарантированный доход.

В настоящий момент интеллектуальная и трудовая деятельность человека видоизменяются. Происходит их взаимопроникновение, стирается грань между интеллектуальной деятельностью и собственно работой или трудом, все чаще проявляются различные виды интеллектуальной деятельности, имеющие свои особенности.

Интеллектуальная деятельность в экономике является прерогативой интеллектуального капитала. Возрастание интеллектуального капитала в процессе постоянного увеличения и совершенствования знаний и способностей благодаря самим способностям к созданию новых знаний происходит в процессе интеллектуальной деятельности, которая возможна не только в производстве, но и чаще - вне его.

Сейчас наступил такой период в развитии экономики и общества, при котором человек должен вкладывать в свой труд не только профессионализм и знания, но все свои человеческие (духовные и интеллектуальные) качества, общение, т.е. фактически - вкладывать всего себя. И уже от этого вклада зависит качество результатов труда [1, с.2]. Не столько потраченное на работу время, сколько «компонент поведения», а также мотивации к деятельности и общению выступают важнейшими факторами профессионального развития человека и создания им стоимости.

Отличительной особенностью интеллектуального и инновационного капиталов человека, по-нашему мнению, является способность к созданию нового, по сравнению с интеллектуаль- ным трудом или интеллектуальной деятельностью, посредством которых можно и создавать новое, и не создавать.

В современном высокоорганизованном производстве (чаще всего на крупных предприятиях) человеческая профессиональная интеллектуальная деятельность разделяется на собственно интеллектуальную, инновационную и научную деятельность, осуществляемую непосредственно в производственном процессе.

Интеллектуальная деятельность - это деятельность интеллектуальных ресурсов человека, она составляет основу и базу развития и функционирования интеллектуального капитала и интеллектуальных ресурсов. Интеллектуальная деятельность происходит в сфере производства продуктов и услуг, но не только в ней. На производстве она представляет собой повседневную деятельность, управленческую, организационную, аналитическую, деятельность, связанную со взаимодействием с людьми, производственными системами и объектами. В сфере услуг (образовательных, услуг здравоохранения, интеллектуальных услуг и других) интеллектуальная деятельность отличается необходимостью большего вклада в общение и взаимодействие между людьми, а также стремлением к наиболее полному удовлетворению потребностей клиентов.

Инновационная деятельность представляет собой частный случай интеллектуальной деятельности, деятельность на острие интеллектуальной мысли, возникающая вместе с приходом к человеу озарения и вдохновения. Это усовершенствование существующих и создание новых 
процессов, технологий, структур, принятие новых решений, модернизация продуктов, услуг, технологий, форм организации труда и производительной деятельности.

Научная деятельность отличается тем, что это глубокая и постоянная интеллектуальная деятельность, характерная для людей с научным складом мышления, которым интересна не повседневная жизнь, а изучение законов и явлений общественной жизни, открытие чего-то принципиально нового и постоянная работа по изучению и исследованию объектов в сфере научных интересов. Научная деятельность на производстве представляет собой научные разработки, создание новых образцов и моделей, конструкторских решений, новых систем, объектов, процессов. Это НИОКР, НИР и прикладные исследования. Фундаментальные исследования проводятся в вузах и научно-исследовательских институтах, где научная деятельность совмешается с преподавательской и образовательной.

Инновационная деятельность на производстве от научной отличается тем, что инновация - это какое-то разовое и небольшое усовершенствование объектов и процессов. Научная же деятельность - это постоянное исследование и создание новых разработок: машин, объектов ИИ, новой техники и технологий.

Научная деятельность, по-нашему мнению, является одной из главенствующих видов интеллектуальной деятельности в современных условиях экономического развития. Для формирования общей картины по научной деятельности в масштабах государства обратимся к статистике научных кадров и научной деятельности организаций.

Согласно данным Мониторинга экономики образования, реализованного НИУ ВШЭ, проведенного по заказу Минобрнауки России, большинство студентов дневных отделений образовательных учреждений высшего образования (58\%) ориентируются на работу в коммерческом секторе. Карьеру в качестве госслужащего планируют около 15\%, собираются пойти в бюджетный сектор 17\%, и лишь десятую часть студентов привлекает карьера в науке [2]. А по результатам опроса общественного мнения, проведенного НИУ ВШэ в рамках Мониторинга инновационного поведения населения, профессию ученого считают удачным карьерным выбором для своего ребенка порядка одной трети граждан (32\%) [3]. Фактический удельный вес выпускни- ков вузов, связавших свою профессиональную карьеру с наукой, остается невысоким: в 2017 г. он не превышал 1\%, а с учетом занимаемых ими исследовательских должностей, еще меньше $0,7 \%[4]$.

На современном этапе развития использование научного потенциала имеет общую тенденцию к замедлению. Число организаций, выполняющих научные исследования и разработки сократилось в 2017 году на 2,18\%, а численность исследователей с учеными степенями уменьшилась почти на 2\% (103327 чел. в 2017 по сравнению с 108388 чел. в 2016). Их снижение продолжается, начиная с 2014 года (109598 чел.). С 2015 года численность кандидатов наук сократилась на 7,47\%, а докторантов - на 7,02\% [5], что также свидетельствует о падении интереса к дальнейшим исследованиям среди взрослого населения и престижности научных званий. Параллельными темпами идет сокращение расходов на науку, причем сильнее уменьшаются средства федерального финансирования (по сравнению с 2014 годом расходы на гражданскую науку из средств федерального бюджета снизились на 13,58\%). Хотя внутренние затраты на исследования в фактически действующих ценах за 2017 год показали небольшой рост на 7,98\%. Рассмотренные показатели представлены в Таблице 1.

Указом Президента Российской Федерации от 07.05.2018 «О национальных целях и стратегических задачах развития Российской Федерации на период до 2024 года» одной из целей научно-технической политики определено обеспечение привлекательности работы в Российской Федерации для российских и зарубежных ведущих ученых и молодых перспективных исследователей. Предпринимаемые в последние годы меры по привлечению и закреплению молодежи в научно-технической сфере, в том числе поддержка молодых кандидатов и докторов наук, способствовали росту числа ученых. Так, за период 2006-2017 гг. численность исследователей в возрасте до 39 лет увеличилась с 117,1 до 157,8 тыс. чел., а их удельный вес в общей численности исследователей - с 30 до 44\% [4].

Сейчас наиболее многочисленную возрастную группу исследователей (91,4 тыс. чел.) составляют лица в возрасте от 30 до 39 лет. За 2006-2017 гг. их численность выросла в 1,8 раза (с 13 до 25\% в общей численности исследователей). Имеется и дальнейший потенциал роста доля исследователей в возрасте до 29 лет увели- 
Таблица 1. Показатели динамики количества научных организаций и численности ученых за последние годы

\begin{tabular}{|c|l|c|c|c|c|}
\hline № & \multicolumn{1}{|c|}{ Показатели / Годы } & 2014 & 2015 & 2016 & 2017 \\
\hline 1 & $\begin{array}{l}\text { Число организаций, выполняющих науч- } \\
\text { ные исследования и разработки, всего }\end{array}$ & 3604 & 4175 & 4032 & 3944 \\
\hline & Темп роста,\% & & 115,84 & 96,57 & 97,82 \\
\hline 2 & $\begin{array}{l}\text { Численность персонала, занятого науч- } \\
\text { ными исследованиями и разработками, } \\
\text { всего }\end{array}$ & 732274 & 738857 & 722291 & 707900 \\
\hline & Темп роста,\% & & 101 & 98 & 98,01 \\
\hline 3 & Численность кандидатов наук, чел. & & 83487 & 80958 & 77251 \\
\hline & Темп роста,\% & 91,71 & 96,97 & 95,42 \\
\hline 4 & Численность докторантов, чел. & 28046 & 27430 & 26076 \\
\hline & Темп роста,\% & 62,64 & 97,8 & 95,06 \\
\hline 5 & $\begin{array}{l}\text { Расходы на гражданскую науку из } \\
\text { средств федерального бюджета, млн. руб. }\end{array}$ & 437273,3 & 439392,8 & 402722,3 & 377882,2 \\
\hline & Темп роста,\% & 100,48 & 91,65 & 93,83 \\
\hline 6 & $\begin{array}{l}\text { Внутренние затраты на научные ис- } \\
\text { следования и разработки в фактически } \\
\text { действующих ценах, млн. руб. }\end{array}$ & 847527,0 & 914669,1 & 943815,2 & 1019152,4 \\
\hline & Темп роста,\% & 107,92 & 103,19 & 107,98 \\
\hline
\end{tabular}

чилась на 1,4\% и в 2017 г. составила примерно $1 / 5$ (или 18\%) от общего числа исследователей.

Тенденция к снижению говорит о том, что при формировании научного и интеллектуального потенциала общества существуют свои проблемы:

1. Недостаточное финансирование научных исследований и программ развития,

2. Отсутствие доступной возможности для реализации и развития человеческого потенциала и капитала у молодых людей, высокие затраты на учебу в вузах, на приобретение второго высшего образования или повышения квалификации, трудности с проведением научных публикаций,

3. Снижение престижа науки в обществе и переток молодежи в более высокооплачиваемые сферы экономики,

4. Общемировая проблема старения научных кадров и недостаток молодых ученых.

Инновационный потенциал по сравнению с научным, имеет гораздо более широкий охват населения, но превращается в инновационный капитал также далеко не в своем полном масштабе, а лишь там, где удается внедрить какое-либо новшество на производстве или коммерциализировать свою идею. Инноватором может стать любой интеллектуально-развитый человек, создавший какое-то усовершенствование, и для этого не требуется специальное научное созна- ние.

Помимо этого, сейчас становится особенно видна разница между творческим и исполнительским трудом. Согласно Вальтуху К.К., который выделяет понятия идеального и материального производства, «творческий труд - первая форма идеального производства». Вторая форма такого производства - это распространение идей и сведений. А исполнительский труд - это уже труд по тиражированию и материализации идей [6], так называемая третья производственная форма.

При этом интеллектуальная деятельность может представлять собой как творческий, так и исполнительский труд, а инновационная деятельность - однозначно труд только творческий. Научная деятельность также в массе своей является творческой, но существует необходимость проведения каких-либо исследований и постановки совсем не творческих задач, и здесь уже деятельность ученого является уже исполнительской.

С Вальтухом К.К. мы согласны также в том, что для любого явления существует идеальная сторона, в связи с чем можно выделить идеальное интеллектуальное производство, возникающее и существующее сначала в ментальном теле человека, в сфере межличностного общения, в процессе обмена идеями и мнениями, а затем переходящее в материальное и существующее в 
физической реальности.

От материального носителя, а также от человека, формальное знание может быть отделено и практически бесплатно размножено в компьютерной форме и без ограничений использовано в какой-либо материальной деятельности в процессе тиражирования. Чем шире оно распространяется, тем выше его общественная полезность. А его товарная стоимость при этом, напротив, по мере распространения, падает, стремясь к нулю, когда знание становится доступным.

Заметим, что изначально знания в принципе не приспособлены к тому, чтобы служить товаром. Затраты на их поиск зачастую трудно определить, а их стоимость как товара невозможно измерить общественно необходимым затраченным трудом. Невозможно установить, где в социальном контексте начинается и заканчивается деятельность по открытию новых знаний. Она может быть совершенно любой непрофессиональной деятельностью: творческой деятельностью, хобби, занятием в свободное время. Кроме того, не существует абсолютной эквивалентности между формами знаний и их содержанием. Зачастую одно знание невозможно заменить другим и каждое из них может считаться несравнимой уникальной ценностью.

Наряду с этим, не только чисто интеллектуальная деятельность существует в производственном процессе, но еще остается и собственно трудовой процесс. Однако такой труд также видоизменяется. Во-первых, сам труд становится автоматизированным, это работа с компьютером и информационными системами, а во-вторых, труд становится работой по управлению автоматизированными процессами и системами, по контролю за качеством их действия, предотвращению непредвиденных ситуаций, выявлению ошибок и их исправлению. Важным является то, что это преимущественно нематериальный труд, работающий в большей степени в идеальном пространстве - с идеями, мнениями и их воплощением.

Современная информатизация промышленного производства все чаще превращает материальный производительный труд, в управление непрерывными потоками информации. Работник-пользователь должен быть постоянно сосредоточен на управлении этими потоками, выказывая внимание и инициативу, которых от него невозможно потребовать приказом или инструкцией. Основным субъектом такого труда выступает он сам, обеспечивая воспроизводство своих профессионально-творческих компетенций и постоянное самосознание. Коммуникация и кооперация между пользователями относятся к самой сути такой деятельности. А «результаты этой деятельности обусловлены прежде всего системой и зависят от отношений между индивидами. Решающую роль здесь играет не общее количество труда, затраченное индивидами, а качество и релевантность коммуникаций, завязывающихся в рамках производственной системы» [1, c.2].

Все это приводит к тому, что современный труд уже невозможно измерить заранее заданными мерилами и нормами. «Сейчас нет возможности объективно определить задачу и оценить результат по отношению к ней. Результат зависит непосредственно от самих людей» [6]. Для его достижения от них требуется самоотдача и соответствующая мотивация. Поскольку способ, которым нужно выполнять задание, не поддается формализации, его нельзя и предопределить. Напротив, теперь предписывается субъективность, т.е. как раз то, что пользователь может произвести не иначе, как «вкладывая себя» в задание [6]. Соответственно, в настоящее время становятся более важными субъективированные человеческие качества: способность к рассуждениям, умение справляться с непредвиденными ситуациями, распознавать и решать проблемы. А «затраченное на труд время уже не может в полной мере считаться мерилом созданной стоимости. Самым важным является качество координации и общения» [6].

Поскольку невозможно измерить произведенную индивидом работу и предписать средства и методы, ведущие к запланированному результату, руководители фирм прибегают к «руководству посредством целей»: они просто «ставят перед сотрудниками цели и предоставляют им самим решать, как их достичь. Отсюда работа в коллективе на предприятиии все более становится похожей на службу» [6].

Приведенные примеры помогают увидеть, что оказание услуг и нематериальный труд (интеллектуальная деятельность) в настоящее время становятся господствующими видами труда, а материальный труд, напротив, оттесняется на обочину производственного процесса или просто перемещается в страны с более дешевой рабочей силой. И хотя без этого труда по-прежнему не обойтись, он, тем не менее, становится 
«подчиненным моментом» производственного процесса. А основой создания стоимости становится нематериальный труд.

При этом сам нематериальный труд в принципе базируется не только на научнотехнических знаниях исполнителей. Скорее, он коренится в способностях общаться и кооперироваться с другими людьми, способностях, относящихся к общей культуре и не являющихся предметом обучения. В этом состоит важное отличие между работниками заводов и служащими современной эпохи. Первые должны были отбросить свою общую культуру, умения и навыки, чтобы подчиниться разделению труда с его повторением операций. Об этом много написано, в особенности у Адама Фергюсона и Эндрю Юра, на которых также опирается Маркс в «Капитале» [6]. В середине XX века подобное разрушение человеческой компетенции, в особенности у сельскохозяйственных рабочих, повторялось в форме строгих дисциплинарных мер.

Теперь же все больше наблюдается отход от шаблонов, стереотипов и четких предписаний и регламентов. Наблюдается повсеместный рост интеллектуальной и творческой деятельности в процессе любого труда, и экономическая сфера дает человеку все большую свободу в деятельности.

С появлением закона о самозанятости [7] ожидается, что на место подчиненного наемного рабочего, получающего зарплату, приходит трудящийся-предприниматель, который сам заботится о своем образовании, повышении квалификации, медицинском страховании и т.д. Он дожен также самостоятельно заниматься поиском для себя работы или доходной деятельности. При этом его деятельность должна представлять собой смесь предпринимательской деятельности, интеллектуальной и инновационной (чтобы идти в ногу со временем он должен самостоятельно вносить новшества в свою деятельность). Он также должен развить в себе и суметь грамотно применять практически все виды человеческого капитала: интеллектуальный, предпринимательский, социальный, витальный, культурный. Уход от разделения труда приводит к тому, что человек единолично должен обладать всеми навыками и знаниями, которые были разделены ранее.

В итоге возникает так называемое «человекпредприятие», а место эксплуатации занимает самоэксплуатация, которая может стать даже сильнее, чем эксплуатация капитализма. Тем не менее, сейчас с упрощением систем связи и инфоматизации общественной жизни многие производственные вопросы могут быть упрощены и самозанятость получает распространение. Явление самозанятости является серьезным шагом на пути ухода от способа производства постиндустриального общества и переходу к информационному обществу и экономике, основанной на знаниях. В новой экономике меняется не только сам способ производства, изменяются также виды человеческой деятельности и происходят перемены в самом человеческом сознании: помимо преобладания нематериального труда и интеллектуальной деятельности делается упор на творческое мышление, научное и инновационно-ориентированное сознание. Это говорит о существенном повышении роли человека в современной и будущей экономической жизни и постепенном уходе от старых форм организации производства и труда.

О том, что отношения найма должны исчезнуть писали еще в начале 1990-х годов Чарльз Хэнди и Уильям Бриджес [8]. По их мнению, должны остаться лишь индивидуальные предприниматели, оказывающие индивидуальные услуги, а каждый работающий человек должен сам отвечать за свое здоровье, свою мобильность, свою способность приспосабливаться к меняющимся местам работы, и за повышение уровня своих знаний. В настоящее время получается, что люди должны управлять всей своей жизнью как человеческим капиталом, постоянно инвестировать в него средства путем курсов повышения квалификации и понимать, что продажная цена их рабочей силы зависит лишь от их усилий и труда.

Крупная фирма сохраняет теперь лишь небольшое ядро постоянных сотрудников с полным рабочим временем. Остальная часть - меняющаяся масса внешних сотрудников с частичной, домашней или удаленной занятостью, самостоятельных, но при этом высококвалифицированных специалистов. Фирма экономит расходы на повышение квалификации, медицинское и пенсионное страхование. Кроме того, работодатель обеспечивает себе возможность значительно изменять требуемый от сотрудников объем работы, не заботясь о законном рабочем времени, т.е. может существенно увеличивать этот объем.

В настоящее время на практике все усиливается тенденция к снижению количества наемно- 
го труда в пользу самопредпринимательства и самозанятости. Процент их среди трудящегося населения также стремительно растет за рубежом - в Великобритании, Италии и Швеции.

Слова А. Горца, по которому самопредпринимательство ведет к тому, что человек и вся его жизнь превращаются в труд, уже сбываются на рынке. Граница между частной жизнью и работой размывается потому, что вся жизнь оказывается в плену экономического расчета и стоимости [1, с. 9].

С 01.01.2019 для самозанятых лиц был введен налог на профессиональный доход [9]. Применять специальный налоговый режим вправе физические лица, в том числе индивидуальные предприниматели и получающие доходы от деятельности, при которой они не имеют работодателя и не привлекают наемных работников. Законом определен ряд ограничений для применения данного спецрежима. Это в том числе реализация подакцизных товаров и товаров, подлежащих обязательной маркировке, добыча и (или) реализация полезных ископаемых, получение доходов, превышающих в текущем календарном году 2,4 миллиона рублей.

Эксперимент с налогообложением самозанятых в некоторых регионах страны уже решено признать удачным - самозанятыми зарегистрировалось около 30000 человек, что в 15 раз больше, чем за полтора года предыдущей попытки, в которой участвовала вся Россия. Начиная с 2020 г. закон о самозанятых заработает на всей территории России. При этом с 01.01.2020 г. будет вводиться штраф за сокрытие налогов: 20\% выручки, а при повторном нарушении за полгода - всей выручки [7].

Однако при этом самостоятельные работники в большинстве случаев зависят от одногоединственного или от очень немногих крупных холдингов, которые подчиняют их чередованию периодов гиперактивности с периодами безработицы. А частные клиенты, которым самостоятельные работники продают свои услуги, сами постоянно подвержены рискам и очень редко обладают постоянной платежеспособностью.

Вместе с тем на самозанятых ложится ответственность за собственную безработицу. Если кто-то окажется безработным, то только по причине недостаточной продаваемости своих знаний. При этом он не получает пособия по безработице, вынужден искать ее самостоятельно и приобретать новые навыки или дополнительное образование.

Среди минусов самозанятости выделяется также и то, что вся деятельность человека практически сводится к одним лишь экономическим целям. А ведь в реальности это далеко не так, существует работа как самореализация, как призвание, помощь ближнему, благотворительность и т.д. А поскольку все люди вносят свой вклад в общественное производство уже тем, что живут в данном обществе, они заслуживают, чтобы этот их вклад был оплачен пособием на существование, а в случае потери работы - пособием на поиск работы. Также самозанятость означает, что за капиталом признается право требовать, чтобы люди развивали свои способности именно так, как это непосредственно выгодно предприятию, и чтобы оно имело право это развитие контролировать. Получается, что человек все равно не является полноправным хозяином своей жизни и вынужден ориентироваться даже не на рыночные потребности, а на потребности того предприятия, у которого есть спрос на его труд, пусть и самостоятельный. Кроме того, работая по найму, многие хотят сделать карьеру, иметь социальные связи и развить руководящие качества, а, работая самостоятельно, им это сделать не удастся, если только не стать владельцем собственной фирмы.

Однако современная тенденция к уменьшению времени на отдых, напряженная трудовая деятельность и необходимость постоянного общения (быть на связи) приводит к тому, что некоторые молодые люди отказываются от карьеры и повышению зарплаты предпочитают увеличение свободного времени и заработок в сети и/или за счет своего дела. Они добровольно уходят с полной ставки на две трети и посвящают себя дому, семье, хобби, отдыху и т.д. Например, учитель, работающий на 2/3 ставки и глубоко убежденный в том, что его интерес к детям и семье в сотни раз ценнее, чем работа в крупной компании. Чем сильнее цифровая экономика определяет действительную реальность, тем больше желающих добровольно уйти из нее. Возникнет новое мировоззрение, изменение образа жизни, режима и мотивации трудовой деятельности и отдыха.

Ввиду непостоянства заработной платы приходит необходимость требования пособия на существование, а затем возникает и право на него. Это указывает на появление новой экономики и конец рыночного общества. При этом право на 
социальное существование новых работников не исчерпывается трудовой деятельностью и не совпадает с ней.

Гарантированный доход призван обеспечить возможность разнообразной деятельности вне рынка, конкуренции и нормирования, той деятельности, которая не может быть предметом обмена и не производит ничего, что можно было бы обменять, измерить или перевести в денежный эквивалент. Возникает лишь вопрос о том, из каких средств этот доход будет выплачиваться.

\section{Библиографический список}

1. Гори А. Знание, стоимость и капитал. К критике экономики знаний. Философско-литературный журнал «ЛОГОС».— № 4(61).-2007. URL: http://www.aitrus.info/node/643

2. Российская молодежь: образование и наука. М.: НИУ ВШЭ, 2017.- С. 51. URL: https://issek.hse.ru/ data/2017/11/08/1158348640/Russian_Youth_Education_and_Science.

3. Российская наука в цифрах. М.: НИУ ВШЭ, 2018 - с. 25. URL: https://issek.hse.ru/mirror/pubs/share/215215010

4. Ратай T.B., Нефедова А.И. Наука технологии Инновации / Экспрес-информация НИУ BШЭ 03.10.2018. URL: https://issek.hse.ru/express_sti

5. Индикаторы науки: 2019: статистический сборник / Л.М. Гохберг, К.А. Дитковский Е.Л. Дьяченко и др.; Нац. исслед. ун-т «Высшая школа экономики».- М.: НИУ ВШЭ, 2019.- 328 с.

6. Вальтух К.К. Информационная теория стоимости и законы неравновесной экономики. М.: ООО «Янус-К»897 c. - C. $159-162$

7. С 2020 года закон о самозанятых заработает по всей России URL: https://zen.yandex.ru/ media/id/5aa8d5d9a86731 ea4d5fd077/s-2020-goda-zakon-osamozaniatyh-zarabotaet-po-vseirossii-5c7149125b728d00afce5e45

8. Фанатичные компании рушат семьи: Чарльз Хэнди о токсичных корпорациях. https://pro.rbc.ru/ demo/5ce4372e9a7947c16b730908

9. Федеральный закон от 27.11.2018 N422-Ф3 «О проведении эксперимента по установлению специального налогового режима «Налог на профессиональный доход» в городе федерального значения Москве, в Московской и Калужской областях, а также в Республике Татарстан (Татарстан)» http://www.consultant.ru/law/ hotdocs/55771.html/ 